\title{
MUDANÇAS CLIMÁTICAS EM CABO VERDE: ANÁLISE DA PERCEPÇÃO DOS ALUNOS DO LICEU NAS ILHAS DE SANTIAGO E SANTO ANTÃO
}

Kátia Regina D’Assunção

Resumo: O objetivo do presente trabalho foi analisar as percepções das atuais mudanças climáticas sobre a população caboverdiana, nomeadamente os alunos do Liceu situados em em três Concelhos da ilha de Santiago e dois Concelhos na ilha de Santo Antão, locais caraterizados pela alta vulnerabilidade e exposição a eventos climáticos extremos. Através deste, foi possível obter uma análise de como os discentes percebem as alterações do clima, bem como os seus riscos. Verificou-se que há um entendimento sobre às mudanças globais e locais do clima, mas deparou-se com a necessidade de uma abordagem mais incisiva por parte da comunidade educativa quanto aos riscos locais e os impactos potenciais nas localidades de estudo.

Palavras-chave: Mudanças Climáticas; Percepção Ambiental; Aquecimento Global.

${ }^{1}$ Câmara Municipal da Boa Vista. E-mail: kathia.regyna@gmail.com 


\section{Introdução}

Às mudanças climáticas de origem antropogênica resultante das emissões na atmosfera de gases com efeito de estufa (GEE) irão acentuar-se ao longo deste século. Essas alterações do clima não são homogêneas e têm impactos distintos em diferentes regiões, as quais apresentam diferentes graus de vulnerabilidade. O Arquipélago de Cabo Verde, localizado na costa ocidental do continente africano, formado por 10 ilhas de origem vulcânica, sofre influência climática direta da região do Sahel, com baixos índices pluviométricos anuais, sendo extremamente vulnerável às mudanças climáticas, pois depende de recursos naturais sensíveis e limitados, como por exemplo os recursos hídricos e a agricultura, além da exposição direta das zonas costeiras.

Os impactos potenciais das mudanças climáticas na região Saheliana segundo o Assessement Report 5 (AR5) do Painel Intergovernamental para as Mudanças Climáticas (IPCC, 2013) são: um aumento das estiagens crônicas, anomalias no regime de chuvas com eventos pontuais mais intensos denominados chuvas torrenciais e aumento do nível médio do mar, que poderão colocar em causa o crescimento socioeconómico e redução da pobreza no País. A inércia em mitigar os riscos e as vulnerabilidades dos impactos da crise climática poderá diminuir as perspectivas das populações e acarretará fortes consequências as comunidades mais desfavorecidas.

No âmbito nacional há reconhecimento sobre a problemática da crise ambiental e suas consequências. Para tal, Cabo Verde ratificou Acordos e Convenções vinculados ao setor do Ambiente e Clima, e estabeleceu políticas nacionais com estratégias favoráveis para assegurar a qualidade ambiental (PANAII, 2011).

Dentro deste contexto, instituições nacionais, comunidade educativa e acadêmica, organizações não-governamentais e representação da sociedade civil realizam significativas iniciativas para informar, sensibilizar e formar diversas esferas da sociedade caboverdiana sobre: ambiente, crise ecológica, problemática da mudança climática global, impactos potenciais e reais para Cabo Verde, a importância da mitigação dos GEE, principalmente na eficiência energética e estratégias de adaptação pertinentes para o país fazer face às intempéries futuras do clima.

Neste âmbito elaborou-se um estudo não exaustivo sobre a percepção das mudanças climáticas e seus riscos com os alunos do $12^{\circ}$ ano do Liceu localizados nos Concelhos de Tarrafal, Santa Cruz e São Lourenço dos Órgãos ilha de Santiago e nos Concelhos do Porto Novo e Ribeira Grande da ilha de Santo Antão, para uma análise sobre como este público percebe o tema dentro da sua complexidade, interpreta dentro da sua subjetividade, associa os riscos inerentes a localidade em que vive e o que ele como ser vivo, cidadão que faz parte e vive no seio da comunidade pode interagir no coletivo, para que a comunidade desenvolva estratégias que venham fazer face aos futuros eventos climáticos extremos. 
O presente estudo preconizou como os discentes do Liceu das zonas de intervenção do projeto percebem o tema, captar o grau de importância do mesmo no cotidiano dos estudantes, e qual é a base metodológica utilizada para a abordagem do tema dentro do ambiente escolar e conclusões e reflexões.

\title{
Contextualização da percepção ambiental sobre o clima
}

O clima, como sistema natural de maior repercussão na vida humana, é entendido por Max Sorre na década de 1950 como a sucessão habitual dos tipos de tempo sobre uma determinada região e seu estudo por um tempo de 30 a 35 anos. De acordo com o tempo, há característica intrínseca que provoca diferentes reações nos seres humanos, seja de pânico, como furacões, ou de euforia, como uma brisa em um dia abafado. Com uma versão lúcida, Orr Jr. (1966: 131) coloca que:

\begin{abstract}
O tempo é um drama em eterna representação, do qual somos o auditório fascinado. Com a atmosfera inferior como palco, o ar e a água como personagens principais, e as nuvens como indumentária, os atos do tempo são apresentados continuamente em algum lugar em redor do globo. O texto é escrito pelo Sol; a produção é dirigida pela rotação da Terra; e, como nenhuma cena de teatro é representada duas vezes da mesma maneira, cada episódio do tempo é interpretado com ligeira diferença, cada um assinalado por um traço de personalidade.
\end{abstract}

Nesse âmbito, entender a tipologia do tempo, bem como entender o ambiente através da percepção do ser humano, vem despertando interesse dos estudiosos desde os primórdios. Os seres humanos, são inseridos num espaço geográfico regido tanto por sistemas naturais quanto por sistemas artificiais e sociais, em que são expostos diariamente a informações, que são captadas através dos órgãos do sentido, e estas, são transportadas ao cérebro, contribuindo para o processo sensitivo/perceptivo/cognitivo do homem (OLIVEIRA, 1998).

No entanto, é importante caracterizar conceitos que atuam na construção da percepção em si, nomeadamente uma distinção entre a percepção e a sensação.

Segundo, Huffman et al. (2003) a sensação, encaixa-se no processo de receber, converter e transmitir informações do mundo externo para o cérebro, através dos sentidos. Embora sensação e percepção estejam intimamente 
associadas e de difícil separação, pode-se classificar a sensação como o processo de detectar e traduzir a informação bruta.

Entretanto, a percepção se dá no sentido à informação sensorial, transformando-a em representações mentais úteis. Tal processo ocorre através de três processos básicos: seleção, organização e interpretação dos dados sensoriais (HUFFMAN et al., 2003).

O primeiro estágio segundo Huffman (op.cit.), da percepção é a seleção, ou seja, escolher os estímulos que mais se vai prestar atenção. Isso ocorre através da atenção seletiva, pois, diante de um excesso de informações sensoriais, o cérebro consegue destacar mensagens importantes.

No processo de organização, a informação é sistematizada em padrões e princípios que ajudam a compreender o mundo. Assim, os dados sensoriais são organizados de acordo com a forma, a constância perceptiva, profundidade e cor.

Finalmente, tem-se a interpretação. Após selecionar e organizar em padrões as informações sensoriais que chegam, o cérebro usa essas informações para explicar e formar juízos sobre o mundo externo. Nesse estágio final, existem diversos fatores que influenciam, como as experiências anteriores, expectativas, cultura, motivações pessoais e padrões de preferência.

Nesse contexto, a percepção é única e intransferível ao ser, pois ela depende do grau de cultura, e ainda, é temporal e vivenciada, ou seja, quanto maior o convívio com determinadas informações ou espaços, maior o processo cognitivo, que é o processo de aprendizagem com as percepções do meio circundante ao ser (TUAN, 1983).

\section{Material e Método de Pesquisa}

O presente trabalho faz parte do Projeto de Reforço das Capacidades de Adaptação e Resiliência às Mudanças Climáticas no setor dos Recursos Hídricos em Cabo Verde, implementado pelo Instituto Nacional de Gestão dos Recursos Hídricos e financiado pelo Programa das Nações Unidas para o Desenvolvimento (PNUD) e pelo Fundo para o Ambiente Global (GEF).

Foram alvos do estudo os Liceus das zonas de intervenção do projeto nas ilhas de Santiago (ST) e de Santo Antão (SA), nomeadamente:

1. Escola Secundária Alfredo da Cruz Silva - Concelho de Santa Cruz (ST);

2. Escola Secundária Luciano Garcia - Concelho de São Lourenço dos Órgãos (ST);

3. Escola Secundária do Tarrafal - Concelho do Tarrafal (ST);

4. Escola Secundária de Coculi - Concelho de Ribeira Grande (SA);

5. Escola Secundária António Silva Pinto - Concelho do Porto Novo (SA).

Revbea, São Paulo, V.10, № 2: 85-94, 2015. 
Considerou para o presente estudo, abordagem junto aos alunos do $12^{\circ}$ ano, pelo fato de entendermos que os mesmos já detêm de conhecimentos mais amplos e abrangente, justamente por estarem na fase conclusiva da vida escolar do ensino secundário.

O estudo baseou-se na coleta de dados por intermédio de um questionário de pesquisa com caráter quantitativo e qualitativo, composto por 10 questões mistas (fechadas e abertas) aplicado entre os dias 10 a 20 de Maio de 2013 aos alunos do $12^{\circ}$ ano do Liceu das áreas de Humanística, Ciência e Tecnologia e Económica e Social, cujo total representa 323 discentes pertencentes as escolas supracitadas. A fim de abranger o maior número possível do total do público-alvo, foram aplicados 261 questionários.

O questionário foi testado e ajustado mediante um processo de pré-teste dividido em três etapas: (i) verificação das perguntas individuais; (ii) aplicação do questionário a um grupo de pessoas e (iii) análise da aplicação e dos resultados, verificando-se o questionário como um todo no que tange à sua validade e condições de aplicação.

$\mathrm{Na}$ primeira parte do instrumento de pesquisa, foram colocadas questões relativas a parte socioeconómicas. A segunda parte do questionário objetivou na informação com relação a tempo, clima e aquecimento global, sendo que a terceira parte perspectivou em levantar dados referentes à percepção e os riscos associados aos impactos potencias das mudanças climáticas.

\section{Resultados e Discussão}

Foram abordados 261 alunos do $12^{\circ}$ ano dos Liceus situados nas zonas de intervenção do projeto nos Conselhos da ilha de Santiago e Santo Antão (Figura 1). Os questionários foram aplicados durante horário escolar com a devida autorização do núcleo dirigente e dos docentes. Dos 261 discentes alvos da pesquisa, 22\% pertence a área de Humanística, 43\% a área de Ciência e Tecnologia e 35\% a área Económica e Social. A idade entre os entrevistados varia entre 16 aos 19 anos, em que $74 \%$ são residentes nas zonas rurais e $68 \%$ apontam como principal fonte de renda familiar as atividades agrícolas.
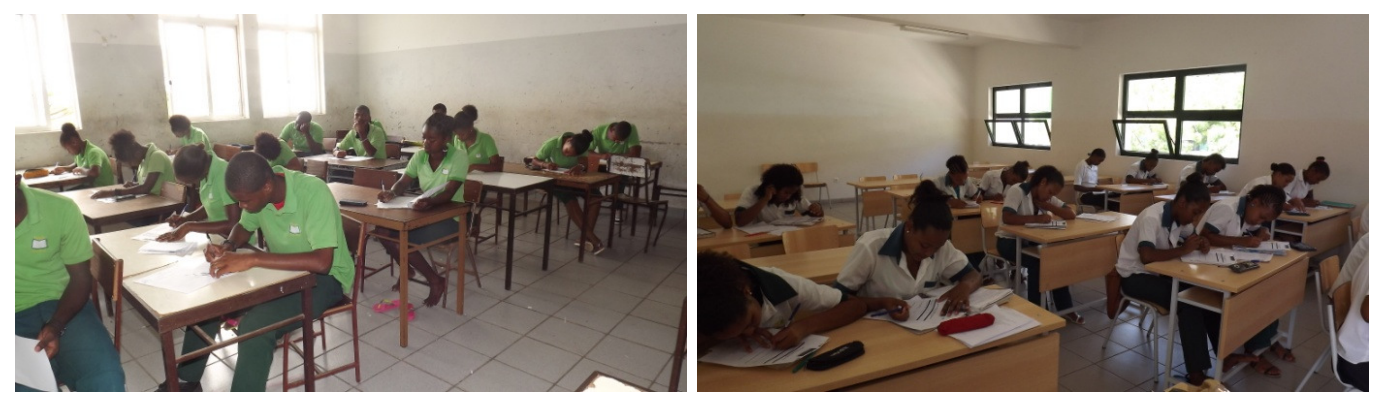

Figura 1: Alunos a preencherem os questionários 
Quando questionados sobre a diferença entre tempo e clima 77\% responderam que sabiam diferenciá-los e $23 \%$ disseram que não conheciam os conceitos de tempo e clima (Figura 2). No entanto, quando foi solicitado para que os entrevistados descrevessem as diferenças entre os dois conceitos, $13 \%$ conseguiram definir as diferenças entre clima e tempo, 29\% responderam incorretamente e 55\% não responderam (Figura 3).

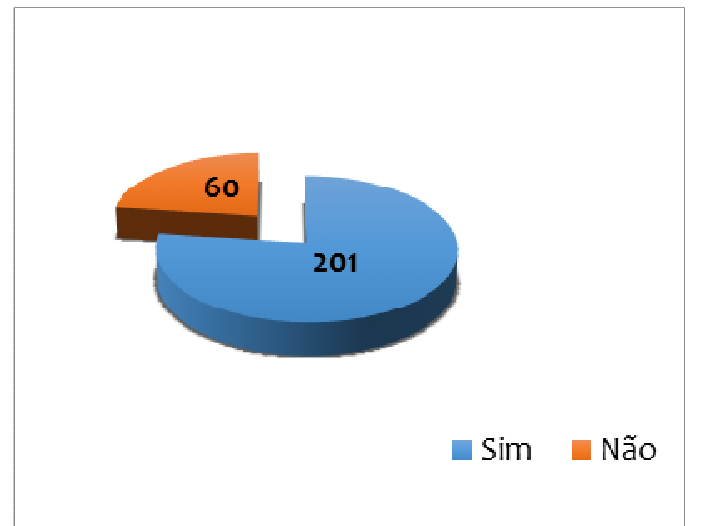

Figura 2: Conhecimento dos conceitos clima e tempo (Valores absolutos).

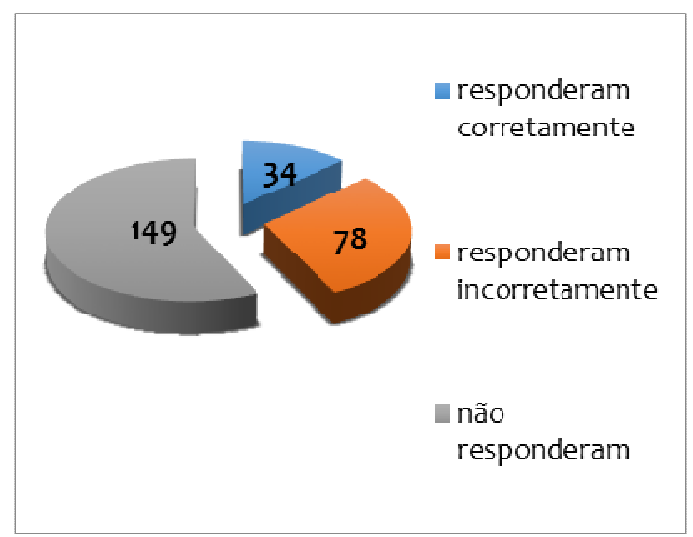

Figura 3: Definição dos conceitos de clima e tempo (Valores absolutos).

Diante da questão sobre os conhecimentos sobre o aquecimento global (AG) e mudanças climáticas (MC), $80 \%$ dos alunos responderam ter conhecimento sobre o assunto, $20 \%$ responderam conhecer o assunto "mais ou menos" e nenhum respondeu não tem conhecimento sobre o assunto (Figura 4). Quanto foram preguntados com a qual principal fonte de informação, $39 \%$ responderam que têm acesso a informação através da televisão, seguido de $32 \%$ que responderam através dos conteúdos do cotidiano escolar professores, $14 \%$ citaram obter informações através de revistas, 7\% responderam através da internet, 6,5\% por meio de leituras de livros e 1,5\% através do rádio, palestras e jornais.

As informações e os conhecimentos que os estudantes adquirem sobre o AG e MC têm sua origem em fontes diversas (Figura 5), três das quais foram citadas pelos estudantes: rádio, palestras e jornais. Tais fontes foram citadas em razão de sua importância nas localidades rurais, onde reside grande parte dos estudantes-alvo da pesquisa. 
(Valores absolutos)

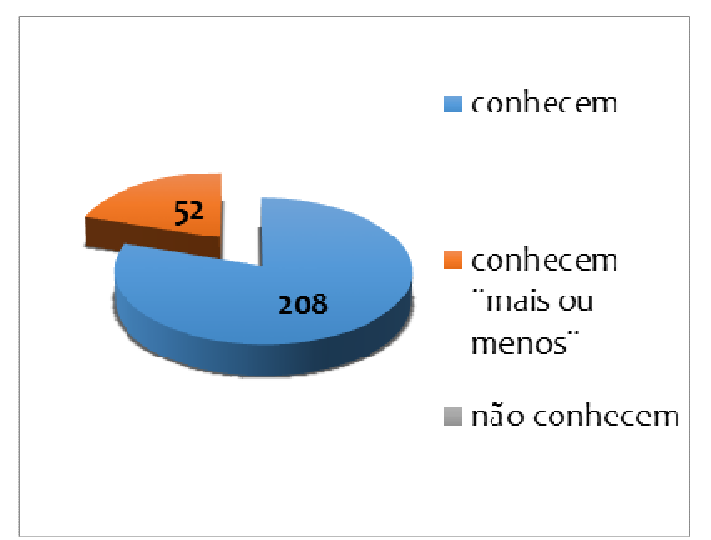

Figura 4: Conhecimento sobre AG (Valores absolutos)

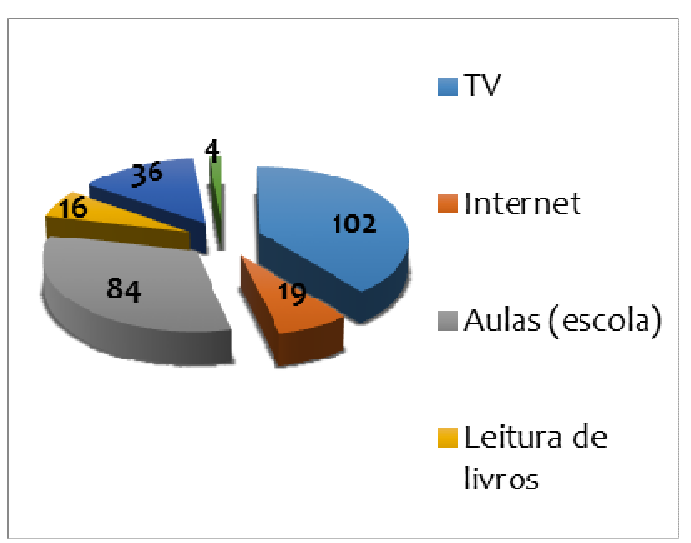

Figura 5: Fonte de informação (Valores absolutos).

Registra-se que 102 estudantes obtiveram conhecimento sobre o AG e a MC por intermédio da televisão, meio de comunicação que mais atinge a população total da amostra. Em oposição, as referências à internet estão menos presentes, em virtude da localização de suas moradias - interior do município, que nem sempre os serviços estão disponíveis.

Observa-se que todos os estudantes obtiveram conhecimentos a respeito do $A G$ e das $M C$ por mais de um meio de comunicação, pois marcaram, no questionário, mais de uma alternativa como "fonte de informação".

Ao responderem descritivamente sobre qual a imagem que vem a mente quando pensam em aquecimento global e mudança do clima, os alunos unanimemente relacionaram a casos trágicos associados a eventos extremos como furacão, ciclones, chuvas e secas. No entanto, atenta-se ao fato de que $33 \%$ dos entrevistados elencaram também, outros fenómenos como o problema da degradação da camada de Ozono, e questões de ordem geológica como incidência de terremotos, maremotos, tsunamis e atividades vulcânicas. Isso mostra que há uma confusão entre a associação dos fenómenos de ordem climática, com os fenómenos de ordem geológica.

No que se refere as causas do $A G$ e da MC, $52 \%$ dos estudantes entrevistados atribuem as causas do $A G$ e da $M C$ aos fatores antrópicos, 
relacionados ao atual padrão de desenvolvimento baseado no consumismo e no extrativismo dos recursos naturais e $36 \%$ responderam que as causas são atribuídas a associação de fatores naturais e antrópicos, 9\% responderam ser resultantes de causas naturais e 13\% atribuíram a outros fatores (Figura 6).

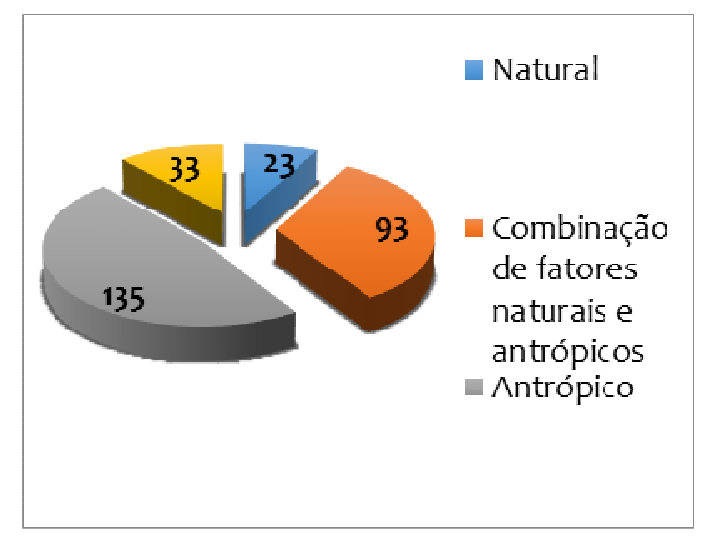

Figura 6: Causas do AG e das MC (valores absolutos).

Quando inquiridos sobre as causas do $A G$ e da $M C$, os estudantes responderam que a mais importante é a queima de combustíveis fósseis. Os estudantes demonstraram ter boa noção de que os gases da combustão não são simplesmente "poluidores do ar", mas agentes intensificadores de um mecanismo natural, o efeito estufa. Verifica-se a mesma noção quando as queimadas são mencionadas como causas importantes do $A G$ e da MC.

Quanto à forma para mitigar o AG, constatou que há um bom entendimento por parte dos alunos, $44 \%$ ao mencionarem a redução das emissões de GEE na atmosfera. Mas, atenta-se que $27 \%$ dos alunos deixaram a questão sem resposta.

Os estudantes do $12^{\circ}$ ano reconheceram, de forma nítida, as seguintes consequências globais do AG - MC: redução das geleiras; elevação dos níveis dos oceanos; escassez de água; epidemias; intensificação das secas, etc.; alagamento das regiões mais próximas ao mar, em alguns países; elevação da incidência de câncer de pele.

Este resultado mostra que os referidos estudantes percebem os conhecimentos que Ihes são mais próximos e que não oferecem grandes dificuldades de compreensão, além de inteligíveis e mais divulgados pela mídia. Exceção feita à "queda da produtividade agrícola" que não foi tão presente dentre as respostas.

Quando questionados sobre os possíveis perigos das MC em Cabo Verde, os entrevistados responderam que a elevação da temperatura, 
alteração na época das chuvas, seguido de mortandade de animais são os principais perigos ao País.

Os estudantes mostram um significativo entendimento com relação a medidas de adaptação para fazer face as MC em Cabo Verde. Porém, pouco foi descrito ao serem questionados quais as medidas adaptativas que tornariam a comunidade onde residem mais resiliente.

\section{Conclusões}

Os estudantes do $12^{\circ}$ ano dos Liceus alvos do estudo demonstraram ter boa percepção do fenómeno aqui em destaque. Quando Ihes foram solicitados responder a respeito do $A G$ e $M C$, apontaram-no com um tema importante, que se coloca entre os mais preocupantes problemas da atualidade.

Ressalva que quando questionados sobre alguns conceitos como clima e tempo, os alunos demonstraram pouco domínio, pouca habilidade em descrever corretamente as diferenciações entre ambos fenómenos. Muito embora, segundo Paulo Freire: "não há saber mais ou saber menos. Há saberes diferentes".

As causas do AG são de domínio dos estudantes, embora, sobre as consequências, falta alguns pormenores na compreensão. As consequências na escala local e que estão diretamente relacionadas ao cotidiano dos estudantes, não foram apontadas como fatores preocupantes (i.e.), com riscos - por exemplo: a "baixa disponibilidade de água", a "queda da produtividade agrícola" e a "migração de espécies animais - peixes".

Se, anos atrás, AG era algo distante, cujas consequências eram representadas a partir de ilustrações futuristas, hoje, de modo geral, pode-se concluir que o $A G$ e às $M C$ são uma realidade bem concreta para o estudante do Liceu. O tema não é mais desconhecido desse público, graças à educação escolar, que cumpre papel importante na ampliação do grau de percepção desses estudantes. No entanto, percebe a necessidade de criar uma rede de discussão para aprofundar as informações sobre o tema.

Outra constatação relevante: a televisão, meio de lazer e entretenimento, supera a internet na busca do conhecimento sobre o AG e às MC, colocando em evidência não apenas a superficialidade do conhecimento que os estudantes tradicionalmente encontram na mídia, mas um relativo atraso no contato com as tecnologias auxiliares do processo ensinoaprendizagem desenvolvido dentro do ambiente educativo.

Desse modo, confirma-se que o tema extremamente relevante nos dias atuais, comparecendo no currículo escolar como conteúdo programático, mesmo que na sombra das disciplinas de ciências e geografia ou mediante 
projetos de meio ambiente, apresenta-se como o início de uma conscientização acerca da crise ecológica que está na base das mudanças climáticas.

É importante que a escola não se limite a enunciar o problema do tema, nem se detenha na sua aparência de problema inevitável, às vezes explorado sob o pretexto de provocar impacto nos estudantes. Talvez seja mais importante debater as causas e consequências do $A G$, das $M C$ como ação destrutiva do homem (sociedade) sobre o espaço natural, o papel de cada um como cidadão e quais os mecanismos de mitigação e adaptação, explorando a percepção que os estudantes demonstram: que o AG é problema causado pelo homem, agravado pela emissão de certos poluentes, impulsionado pelos altos níveis de consumo de combustíveis fósseis, etc.

\section{Referências}

ANTUNES, A. Leitura do mundo no contexto da planeterização: por uma pedagogia da sustentabilidade. São Paulo, FEUSP, 2002 (Tese de Doutorado).

ANTUNES, A. Sementes de primavera: cidadania desde a infância. São Paulo: Instituto Paulo Freire, 2009.

BOFF, L. Saber cuidar: ética do humano, compaixão pela terra. Petropolis, Vozes, 1999.

CAPRA, F. The Web of Life: a New Scientific Understanding of Living Systems. New York: Anchor Books, 1996.

DE MOORE, E. O Jardim como currícul”. Revista Pátio. Porto Alegre, no. 13, maio julho 2000, pp. 1115, 2000.

FREIRE, P. Pedagogia da Autonomia. São Paulo: Paz e Terra, 1997

FREIRE, P. Pedagogia do oprimido. Rio de Janeiro: Paz e Terra, 1975

GADOTTI, M. Pedagogia da Terra. São Paulo: Peirópolis, 2001.

HUFFMAN, K.; VERNOY, M.; VERNOY, J. Psicologia. São Paulo: Atlas, 2003.

OLIVEIRA, L.; DEL RIO, V. (Orgs.). Percepção ambiental: a experiência brasileira. São Carlos. Studio Nobel, 1996.

ORR Jr., C. Entre a Terra e o Espaço. Rio de Janeiro Livro Editora, 1966.

RODRIGUES, L.C.; CAETANO, P.F. Influência do Clima no Comportamento dos Estudantes da UnB (Série: Textos de Alunos da Disciplina Psicologia Ambiental). Brasília, DF: UnB, 1998. Laboratório de Psicologia Ambiental.

SATO, M.; CARVALHO, I. Educação Ambiental: Pesquisas e Desafio. Porto Alegre. Artmed, 2005. 